\title{
Are interstitial lung abnormalities associated with COPD? A nested case-control study
}

\author{
This article was published in the following Dove Press journal: \\ International Journal of COPD \\ 26 May 2016 \\ Number of times this article has been viewed
}

\author{
Francesca Bozzetti' \\ Ilaria Paladini' \\ Enrico Rabaiotti ${ }^{2}$ \\ Alessandro Franceschini' \\ Veronica Alfieri ${ }^{3}$ \\ Alfredo Chetta ${ }^{3}$ \\ Ernesto Crisafulli ${ }^{3}$ \\ Mario Silva ${ }^{2}$ \\ Ugo Pastorino ${ }^{4}$ \\ Nicola Sverzellati' \\ 'Section of Radiology, Department \\ of Surgical Sciences, University of \\ Parma, ${ }^{2}$ Department of Radiology, \\ Academic Hospital of Parma, \\ ${ }^{3}$ Respiratory Disease and Lung \\ Function Unit, Department of Clinical \\ and Experimental Medicine, University \\ of Parma, Parma, ${ }^{4}$ Division of Thoracic \\ Surgery, Fondazione IRCCS Istituto \\ Nazionale dei Tumori, Milan, Italy
}

Correspondence: Nicola Sverzellati Section of Radiology, Department of Surgical Sciences, University of Parma, Padiglione Barbieri, Via Gramsci I4, Ospedale Maggiore di Parma, 43I26 Parma, Italy

Tel +390521702417

Email nicola.sverzellati@unipr.it
Purpose: In this study, we tested the association between COPD and interstitial lung abnormality (ILA), notably in relation to the presence of computed tomography (CT) signs of lung fibrosis.

Patients and methods: COPD cases were selected from participants undergoing lung cancer screening (Multicentric Italian Lung Detection trial) for airflow obstruction ( $\mathrm{n}=311 / 2,303,13.5 \%$ ) and 146 consecutive patients with clinical COPD. In all, 457 COPD cases were selected and classified according to the stages of Global Initiative for Chronic Obstructive Lung Disease. A nested matching (case: control =1:2) according to age, sex, and smoking history was operated between each COPD case and two control subjects from Multicentric Italian Lung Detection trial without airflow obstruction. Low-dose CT scans of COPD cases and controls were reviewed for the presence of ILA, which were classified into definite or indeterminate according to the presence of signs of lung fibrosis.

Results: The frequency of definite ILA was similar between COPD cases and controls $(P=0.2)$, independent of the presence of signs of lung fibrosis $(P=0.07)$. Combined definite and indeterminate ILA was homogeneously distributed across Global Initiative for Chronic Obstructive Lung Disease stages $(P=0.6)$. Definite ILA was directly associated with current smoker status (odds ratio [OR] 4.05, 95\% confidence interval [CI]: 2.2-7.4) and increasing pack-years (OR $1.01,95 \%$ CI: 1-1.02). Subjects with any fibrotic ILA were more likely to be older (OR 1.17, 95\% CI: 1.10-1.25) and male (OR 8.58, 95\% CI: 1.58-68.9).

Conclusion: There was no association between COPD and definite ILA. However, low-dose CT signs of lung fibrosis were also observed in COPD, and their clinical relevance is yet to be determined.

Keywords: interstitial lung abnormality, chronic obstructive lung disease, usual interstitial pneumonia, airspace enlargement with fibrosis

\section{Introduction}

COPD is a common, mostly preventable and treatable, chronic disease characterized by persistent airflow limitation. COPD is usually progressive and associated with an enhanced chronic inflammatory response to noxious particles or gases by the airways and alveola. ${ }^{1}$ Exacerbations and comorbidities contribute to the overall severity. In particular, COPD-related comorbidities impact the patients' management and prognosis, especially as the airway obstruction becomes more severe. ${ }^{2,3}$ However, these comorbidities may be overlooked as their clinical features often overlap within one another and COPD. In this regard, the relationships between cigarette smoking and heart disease, lung cancer, and COPD are well known.,

Although prevalence data of interstitial lung abnormality (ILA) in asymptomatic smokers are increasing (largely due to the ongoing computed tomography [CT]-based 
lung cancer screening trials), there are scant data about the relationship between ILA and COPD. ${ }^{6-8}$ In a study of 2,416 COPDGene participants who were cigarette smokers, ILA was found in 194 subjects ( $8 \%$ ). The prevalence of ILA increased with age, tobacco exposure, and current smoking status. Subjects with ILA were more likely to have a restrictive lung deficit on pulmonary function tests (PFTs) and were less likely to meet Global Initiative for Chronic Obstructive Lung Disease (GOLD) criteria for COPD. ${ }^{6}$ Since then, updates have been published for classification of fibrotic lung disease. ${ }^{9,10}$ Therefore, validation of relation between smoking-related ILA and COPD should be investigated in the light of the new references.

The purpose of this nested case-control study was to evaluate the association between COPD and ILAs by means of low-dose CT (LDCT), with specific focus on the radiological fibrotic pattern.

\section{Patients and methods}

Clinicoradiological data of the present study were retrieved from the databases of two studies: 1) lung cancer screening trial called Multicentric Italian Lung Detection (MILD) trial, at the Fondazione IRCCS Istituto Nazionale dei Tumori of Milan and 2) CT study on patients with COPD, at the Academic Hospital of Parma. Both studies were approved by each institutional review board (Fondazione IRCCS Istituto Nazionale Tumori di Milano and Parma, repectively), and the written informed consent was waived for the retrospective examination of the analyzed data. The study cases included all the subjects with COPD consecutively recruited in the MILD trial between September 2005 and January 2013 (Figure 1). All analyses were performed using the 1:2 matched set between cases (MILD participants with airflow obstruction at baseline PFTs) and controls (MILD participants without airflow obstruction at baseline PFTs). Age ( \pm 5 years), sex, smoking status (ie, current or former smokers), and pack-years $( \pm 5)$ were used for matching cases to controls. MILD eligibility criteria included age 49-75 years, current or former smokers (having quit smoking within 10 years before the recruitment) with $\geq 20$ pack-years of smoking history, and no history of cancer within the prior 5 years. Details of MILD trial are given elsewhere. ${ }^{11,12}$ Part of the LDCTs of the MILD subjects included in this study population were also analyzed by other observers in a previous study addressing a similar hypothesis. ${ }^{8}$

Since limited subjects with severe airflow limitation were present in the MILD trial, we added clinical subjects with the aim of evaluating a broader range of COPD. All the consecutive patients with COPD who underwent both PFTs and LDCT (within 30 days of PFTs) for another study on the relationship between COPD and lung cancer at the Academic Hospital of Parma between March 2009 and December 2012 were also matched to MILD controls (as done for the MILD cases).

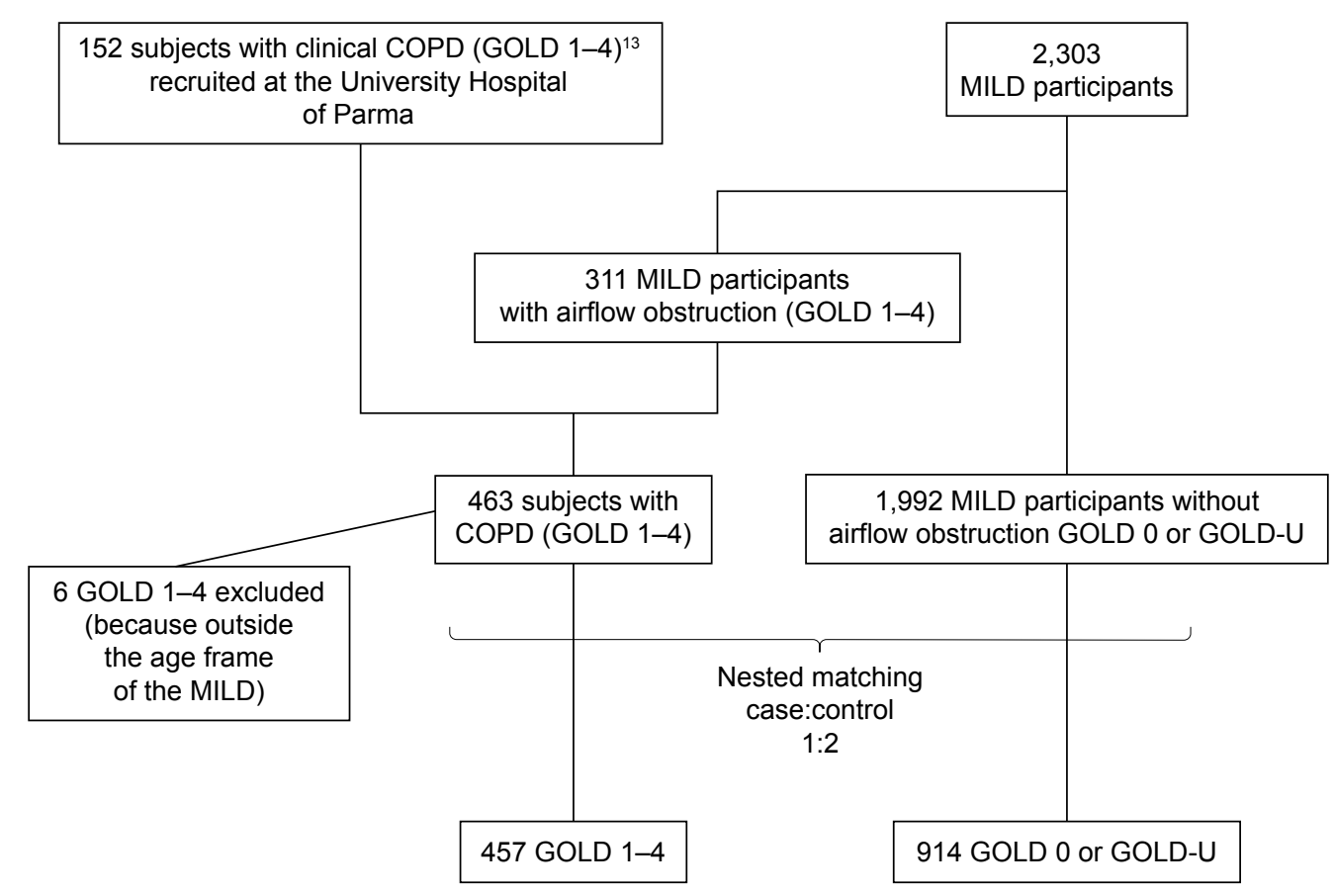

Figure I A CONSORT diagram illustrating the selection of patients included in the data analysis.

Abbreviations: CONSORT, Consolidated Standards Of Reporting Trials; GOLD, Global Initiative for Chronic Obstructive Lung Disease; MILD, Multicentric Italian Lung Detection; GOLD-U, GOLD unclassified. 


\section{Pulmonary function test}

Lung function was measured at baseline in all MILD participants using a flow spirometer (KoKo; nSpire Health, Longmont, CO, USA), while clinical patients from Parma underwent full PFTs through a plethysmograph (Vmax 6200; SensorMedics, Yorba Linda, USA). Forced expiratory volume in 1 second $\left(\mathrm{FEV}_{1}\right)$ and forced vital capacity $(\mathrm{FVC})$ were expressed as percentage of the predicted value.

Subjects were classified according to the GOLD stages. ${ }^{13}$ Controls were defined by a postbronchodilator $\mathrm{FEV}_{1} /$ $\mathrm{FVC} \geq 0.7$ and $\mathrm{FEV}_{1} \% \geq 80 \%$ predicted (GOLD 0 ). Cases were COPD subjects within GOLD stages 1-4. Additionally, subjects with an $\mathrm{FEV}_{1}<80 \%$ predicted and $\mathrm{FEV}_{1} / \mathrm{FVC} \geq 0.7$ were classified as GOLD unclassified (GOLD U). ${ }^{14}$

\section{LDCT scanning}

The study subjects underwent imaging with 16- to 128-detector row CT scanners (Definition 16 or Sensation 64, Flash 128; Siemens Medical Solutions, Forchheim, Germany). Images were obtained during breath hold at full inspiration in the supine position. Acquisition parameters were as follows: tube voltage, $120-140 \mathrm{kVp}$; tube current, 30-100 mAs; and collimation, $0.6-1 \mathrm{~mm}$. Reconstruction parameters were as follows: kernel, medium/high resolution (B50f); slice thickness, $1 \mathrm{~mm}$; and slice interval, $1 \mathrm{~mm}$. The axial images were reviewed by using a Digital Imaging and Communications in Medicine viewer (RadiAnt DICOM viewer, Version 1.1.8.46.46, 64b, Medixant, Poznan, Poland) with window level $-600 \mathrm{HU}$ and window width 1,600 HU.

\section{Image review}

Two pairs of radiologists - each constituted by a junior (IP, 1 year of experience; FB, 3 years of experience) and an experienced chest radiologist (NS, 10 years of experience; ER, 20 years of experience) - reviewed in consensus the anonymized LDCTs for the presence of ILA as follows: 450 LDCTs by radiologists pair 1 (IP and ER) and 921 LDCTs by radiologists pair 2 (FB and NS). LDCTs were scored as follows: no evidence of ILA, equivocal for ILA, or definite ILA. Findings equivocal for ILA were defined as focal or unilateral ground glass opacity (GGO), focal or unilateral reticulation, and patchy GGO ( $<5 \%$ of the lung); an individual pattern consisting of conspicuous reticular abnormalities admixed with emphysema (termed airspace enlargement with fibrosis [AEF]) was considered as equivocal ILA and individually recorded. ${ }^{7,9,15}$ Definite ILA LDCT features included GGO that affected $>5 \%$ of any lung zone, nondependent subpleural reticular abnormality, diffuse centrilobular nodularity with or without GGO, honeycombing, traction bronchiectasis, nonemphysematous cysts, or signs of architectural distortion (eg, fissure displacement related to any reticular abnormality). ${ }^{7}$ Distribution prevalence was classified as follows: the upper lung zone (when most of the findings were above the level of the tracheal carina), the lower lung zone (when most of the findings were below the level of the tracheal carina), or diffuse. The definite ILA was classified into the following predominant LDCT patterns: definite usual interstitial pneumonia (UIP), possible UIP, respiratory bronchiolitis (RB), and indeterminate (Table 1). ${ }^{9,16}$ Any ILA was subclassified as "fibrotic ILA" (GGO and/or intralobular reticular abnormality with traction bronchiectasis or signs of architectural distortion and honeycombing) and "nonfibrotic ILA" (GGO, centrilobular opacity, and/or reticular abnormality without traction bronchiectasis or signs of architectural distortion)..$^{10}$

\section{Statistical analysis}

Comparative analysis of demographic and functional data was performed by unpaired $t$-test, analysis of variance (ANOVA) analysis, or a chi-square test with Fisher's exact test as

Table I Classification of LDCT patterns in subjects with definite and equivocal ILA

\begin{tabular}{ll}
\hline $\begin{array}{l}\text { Predominant } \\
\text { LDCT pattern }\end{array}$ & LDCT features \\
\hline $\begin{array}{l}\text { Definite UIP } \\
\text { pattern }\end{array}$ & $\begin{array}{l}\text { Predominant lower lung zone subpleural reticular opacities and honeycombing } \\
\text { With or without traction bronchiectasis/bronchiolectasis and signs of architectural distortion (eg, lung fissure displacement) } \\
\text { Focal ground glass }\end{array}$ \\
$\begin{array}{l}\text { Possible UIP } \\
\text { pattern }\end{array}$ & $\begin{array}{l}\text { With or without traction bronchiectasis/bronchiolectasis and signs of architectural distortion (eg, lung fissure displacement) } \\
\text { Focal ground glass }\end{array}$ \\
RB & $\begin{array}{l}\text { Predominant upper middle lung zone fluffy centrilobular nodules with or without GGO } \\
\text { Any combination of features that do not fit UIP or RB patterns and do not consist of AEF } \\
\text { (eg, bilateral GGO and predominant upper lung zone subpleural reticular opacities) }\end{array}$ \\
\hline
\end{tabular}

Abbreviations: LDCT, low-dose computed tomography; ILA, interstitial lung abnormality; UIP, usual interstitial pneumonia; RB, respiratory bronchiolitis; GGO, ground glass opacity; AEF, airspace enlargement and fibrosis. 
appropriate. Adjusted logistic regression models were calculated to assess the association between definite ILA or any (ie, combined definite and indeterminate) fibrotic ILA and demographics (age, sex, BMI, smoking status, and pack-years) and lung function ( $\mathrm{FEV}_{1} \%$ and the presence of airflow obstruction). Age and pack-years of smoking were evaluated as continuous variables. The corresponding odds ratios (ORs) with 95\% confidence interval (CI) were computed. Furthermore, factors associated with the presence of definite ILA were analyzed for cases only. Analyses were performed using MedCalc (Version 9.5.2.0; MedCalc Software, Mariakerke, Belgium) and SPSS Statistics (Version 17.0; SPSS Inc., Chicago, IL, USA) software.

\section{Results}

The demographic characteristics of the study subjects are summarized in Table 2. The final study population included a total of 457 cases matched to 914 controls (Figure 1). A total of 311 out of $457(60.1 \%)$ cases were MILD participants, whereas the remainder 146 out of 457 (31.9\%) cases were clinical COPD subjects consecutively recruited at the University Hospital of Parma. All subjects were white Caucasians. At the best of the multiparametric matching process, cases were older than controls $(P<0.001)$, heavier smokers $(P=0.01)$, and more frequently former smokers $(P=0.0009)$.

The classification of LDCT patterns is summarized in Table 3. The definite UIP pattern was found in two out of $914(0.2 \%)$ controls only, while the possible UIP pattern in four out of $457(0.9 \%)$ cases (Figure 2) and eight out of 914 $(0.9 \%)$ controls (Figure 3$)$. Signs consistent with RB were more frequent in controls $(P=0.04$; Figure 4$)$, whereas the indeterminate pattern was more frequent in cases $(P=0.006)$. In particular, the LDCT pattern was classified as indeterminate in 12 out of $115(10.4 \%)$ cases with definite ILA because of either predominant ground glass opacities or predominant upper lung zone abnormalities. Individual LDCT features are summarized in Table S1. Equivocal ILAs were observed only among cases (14 out of 457, 3\%), with eight out of $14(60 \%)$ equivocal ILAs being consistent with AEF (Figure 5) and the remainder six out of 14 (40\%) showing unilateral opacity. Overall, the frequency of definite ILA was similar between cases and controls $(P=0.2$; Table 4) as well as among the study subgroups (ie, COPD cases, MILD subjects with airflow obstruction, and subjects without airflow obstruction, $P=0.2$ ). This was also true for any (ie, both definite and equivocal) fibrotic ILAs between cases and controls $(P=0.07)$. Any (ie, combined definite and indeterminate) ILA did not differ in terms of frequency across GOLD stages $(P=0.6)$, whereas any fibrotic ILA was less frequent in controls as compared to subjects with GOLD 1, 2, 3, or $\mathrm{U}(P=0.03$; Figure 6 and Table S2).

As compared with subjects without any ILA, those with any ILA were more frequently men, current smokers, and had a greater amount of exposure to tobacco smoke (Table 4). At adjusted logistic regression analysis, current smoking status (OR 4.05, 95\% CI: 2.2-7.4) and increasing pack-years (OR 1.01, 95\% CI: 1-1.02) were factors associated with the presence of definite ILA (Table 5). Subjects with any fibrotic ILA were more likely to be older (OR 1.17, 95\% CI: 1.10-1.25) and men (OR 8.58, 95\% CI: 1.58-68.9).

Table 2 Characteristics of cases vs controls

\begin{tabular}{|c|c|c|c|}
\hline Variables & $\begin{array}{l}\text { Subjects with airflow } \\
\text { obstruction (cases) }\end{array}$ & $\begin{array}{l}\text { Subjects without airflow } \\
\text { obstruction (controls) }\end{array}$ & $P$-value \\
\hline \multicolumn{4}{|l|}{ Sex, n (\%) } \\
\hline Female & $154(33.5 \%)$ & $306(66.5 \%)$ & 0.9 \\
\hline Male & $303(33.3 \%)$ & $608(66.7 \%)$ & \\
\hline Age, years, mean $\pm S D$ & $63.2 \pm 7.4$ & $57.9 \pm 6.2$ & $<0.001$ \\
\hline $\mathrm{BMI}$, mean $\pm \mathrm{SD}$ & $26 \pm 4.2$ & $26.4 \pm 4$ & 0.4 \\
\hline \multicolumn{4}{|l|}{ Smoking status, $\mathrm{n}$} \\
\hline Current & 263 & 635 & 0.0009 \\
\hline Former & 194 & 279 & \\
\hline \multicolumn{4}{|l|}{ Pack-years of smoking } \\
\hline Mean \pm SD & $48.3 \pm 24.2$ & $44 \pm 20.7$ & 0.01 \\
\hline \multicolumn{4}{|l|}{$\mathrm{FEV}_{1} \%$} \\
\hline Mean \pm SD & $80.4 \pm 19.1$ & $101.4 \pm 14.2$ & $<0.000$ I \\
\hline \multicolumn{4}{|l|}{ FVC\% } \\
\hline Mean \pm SD & $104.2 \pm 18.3$ & $104.8 \pm 17.2$ & 0.1 \\
\hline \multicolumn{4}{|l|}{$\mathrm{FEV}_{1} / \mathrm{FVC}$} \\
\hline Mean \pm SD & $59.6 \pm 8.8$ & $79.3 \pm 7.9$ & $<0.000$ I \\
\hline
\end{tabular}

Abbreviations: BMI, body mass index; FEV , forced expiratory volume in I second; FVC, forced vital capacity; FEV /FVC, Tiffenau index; SD, standard deviation. 
Table 3 LDCT patterns frequency

\begin{tabular}{|c|c|c|c|}
\hline LDCT patterns & $\begin{array}{l}\text { Subjects with airflow } \\
\text { obstruction ( } n=457 \text { cases) }\end{array}$ & $\begin{array}{l}\text { Subjects without airflow } \\
\text { obstruction ( } n=9 \mid 4 \text { controls) }\end{array}$ & $P$-value ${ }^{a}$ \\
\hline Definite ILA, n (\%) & $32(7 \%)$ & $83(9 \%)$ & 0.22 \\
\hline Definite UIP, n (\%) & - & $2(0.2 \%)$ & $\mathrm{N} / \mathrm{A}$ \\
\hline Possible UIP, n (\%) & $4(0.9 \%)$ & $8(0.9 \%)$ & 0.2 \\
\hline RB, n (\%) & $21(4.6 \%)$ & $71(7.8 \%)$ & 0.04 \\
\hline Indeterminate, n (\%) & $9(2 \%)$ & $3(0.3 \%)$ & 0.006 \\
\hline Fibrotic ILA, n & 4 & 12 & 0.6 \\
\hline Equivocal ILA, n (\%) & $14(3.1 \%)$ & - & $<0.000 \mathrm{I}$ \\
\hline AEF, n (\%) & $8(1.7 \%)$ & - & 0.02 \\
\hline Unilateral opacities, n (\%) & $6(1.3 \%)$ & - & $\mathrm{N} / \mathrm{A}$ \\
\hline Fibrotic ILA, n (\%) & $9(1.9 \%)^{\mathrm{a}}$ & - & $<0.0001$ \\
\hline
\end{tabular}

Note: ${ }^{a}$ In two cases, unilateral reticulation and AEF coexisted.

Abbreviations: LDCT, low-dose computed tomography; ILA, interstitial lung disease; UIP, usual interstitial pneumonia; N/A, not applicable; RB, respiratory bronchiolitis; $\mathrm{AEF}$, airspace enlargement with fibrosis.

By limiting the analysis to cases, the current smoking status (OR 3.04, 95\% CI: 1.17-7.85) and increasing pack-years of smoking (OR 1.01, 95\% CI: 1-1.03) were predictive factors of definite ILA (Table 6). The presence of airflow obstruction was associated with neither definite ILA nor any fibrotic ILA in the adjusted models.

\section{Discussion}

In this nested case-control study, there was no association between ILA and COPD in smokers. We observed signs of definite ILA on LDCT in $7.5 \%$ of the COPD subjects. These findings are similar and add weight to the study by Washko et $\mathrm{al}^{6}$ who reported definite ILAs in $7.3 \%$ of a large study population of GOLD 1-4 stages COPD subjects. Additionally, our study provides more detailed data about the prevalence of fibrotic ILA in COPD, namely, $2.8 \%$ in total or $0.9 \%$ when the sole definite fibrotic ILAs were considered.
In line with the study by Washko et $a 1,{ }^{6}$ the presence of a definite ILA was not associated with odds of meeting COPD. Indeed, the ILA frequency was similar across GOLD 1-4 stages. Of note, no signs of ILA were observed in GOLD 4 COPD. In contrast with the findings from Washko et al, subjects with definite ILA were not likely to meet the GOLD U criteria. However, both latter observations are limited by the small number of subjects in these functional stages. Furthermore, we showed that the prevalence of definite ILAs was similar across the study subgroups, in particular between patients with symptomatic COPD and asymptomatic participants to lung cancer screening, thus strengthening the primary observation of this study. Therefore, these findings suggest that COPD is not a risk factor for ILA.

Although the lack of association between COPD and ILA is obvious on a functional basis, it is noteworthy that ILA may be missed in smokers through standard clinical-functional
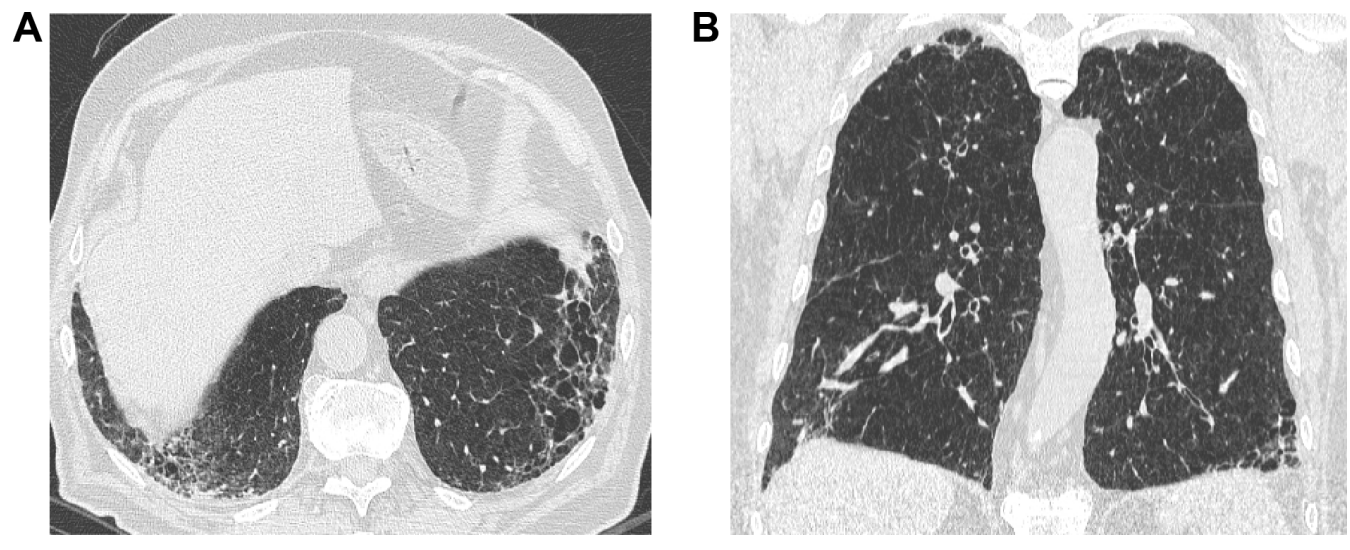

Figure 2 A 57-year-old former male smoker with clinical chronic obstructive lung disease (COPD).

Notes: (A) Both study observers jointly considered the thick-walled low attenuation areas in the lower lobes as consistent with reticular opacities superimposed to pulmonary emphysema (ie, not as honeycombing). (B) The latter was also abundant in the upper middle lung regions. The LDCT pattern was indeed rated as possible UIP. Abbreviations: LDCT, low-dose computed tomography; UIP, usual interstitial pneumonia. 


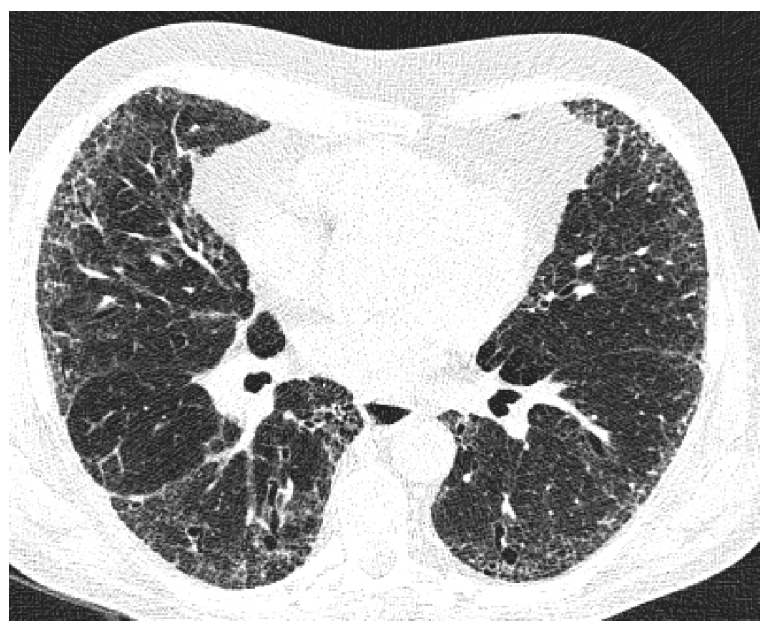

Figure 3 A 67-year-old male current smoker with no airflow obstruction on PFT (control) and a possible UIP pattern on LDCT.

Note: Subpleural basal reticular opacities containing traction bronchiectasis without evidence of honeycombing can be appreciated.

Abbreviations: PFT, pulmonary function test; UIP, usual interstitial pneumonia; LDCT, low-dose computed tomography.

assessment, in particular for those with COPD. ${ }^{17}$ Indeed, ILA may be mild with no effect on lung volumes. ${ }^{6,18}$ Furthermore, it is still not clear which proportions of emphysema and ILA are required to produce either predominant obstructive or predominant restrictive functional pattern. The broad distribution of participants with ILAs on a plot of $\mathrm{FEV}_{1} \%$ (as a percentage of the predicted value) against the ratio of $\mathrm{FEV}_{1} / \mathrm{FVC}$ suggests that spirometry alone is not helpful in classifying ILA in smokers (Figure 6). This observation is limited by the lack of full pulmonary function data (eg, total lung capacity and residual volume) and emphysema in the present study that would have clarified the relationship between ILA and the restrictive functional pattern.

In keeping with the study by Washko et al, ${ }^{6}$ the current smoking status was the strongest factor associated with

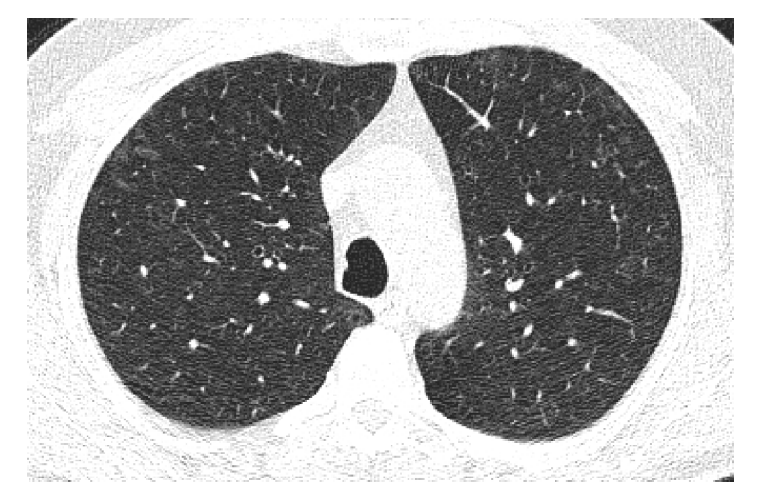

Figure 4 A 59-year-old control current female smoker with an LDCT showing patchy GGO and poorly defined centrilobular nodules consistent with signs of RB. Abbreviations: LDCT, low-dose computed tomography; GGO, ground glass opacity; RB, respiratory bronchiolitis.

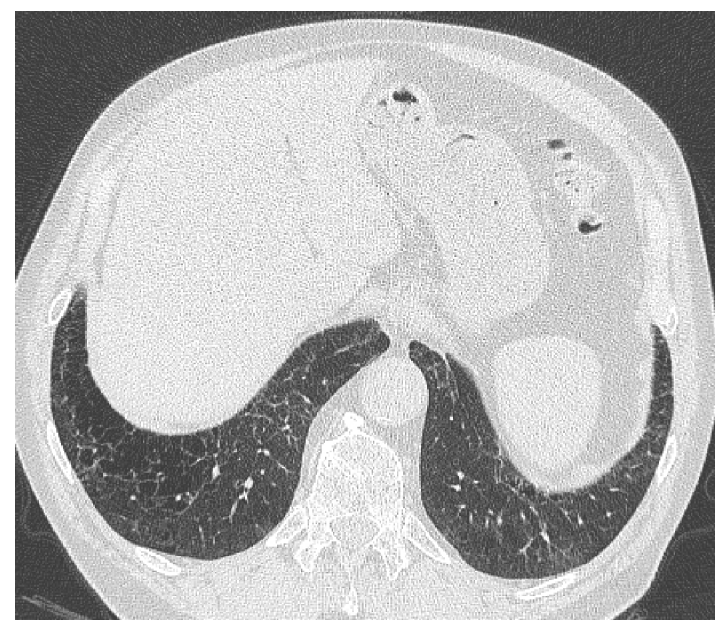

Figure 5 An axial LDCT image of a 79-year-old former male smoker with clinical COPD showing thick-walled, bizarre-shaped emphysematous areas in the right lower lobe that were regarded as consistent with AEF.

Abbreviations: LDCT, low-dose computed tomography; AEF, airspace enlargement with fibrosis.

definite ILA in the group of cases. Furthermore, in the whole study population, the positive associations with both current smoking status and higher pack-years strengthen the hypothesis that such ILAs are smoking related. This observation is particularly true considering that cases were matched to controls for smoking history.

To better understand the clinical significance of the ILA in smokers, it is important to clearly distinguish CT abnormalities that are likely to be reversible (eg, after smoking cessation) from those that are not. Washko et $\mathrm{al}^{6}$ found definite ILA on CT images in 13.4\% (89 of 660) of cigarette smokers with GOLD 1-4 COPD. Most of the abnormalities in these

Table 4 Characteristics of subjects stratified for the presence of ILA

\begin{tabular}{|c|c|c|c|}
\hline Variables & $\begin{array}{l}\text { Subjects } \\
\text { with any ILA } \\
(n=\mid 29)\end{array}$ & $\begin{array}{l}\text { Subjects } \\
\text { with no ILA } \\
(n=I, 242)\end{array}$ & P-value \\
\hline \multicolumn{4}{|l|}{$\operatorname{Sex}(n)$} \\
\hline Female & 33 & 427 & 0.04 \\
\hline Male & 96 & 815 & \\
\hline Age, years (mean $\pm S D)$ & $59.8 \pm 7.6$ & $59.6 \pm 7$ & 0.8 \\
\hline $\mathrm{BMI}($ mean $\pm \mathrm{SD})$ & $25.9 \pm 3.6$ & $26.3 \pm 4.2$ & 0.07 \\
\hline \multicolumn{4}{|l|}{ Smoking status (n) } \\
\hline Current & 109 & 791 & $<0.0001$ \\
\hline Former & 20 & 433 & \\
\hline $\begin{array}{l}\text { Pack-years of smoking } \\
\text { (mean } \pm S D)\end{array}$ & $49.5 \pm 24$ & $44.9 \pm 21.7$ & 0.03 \\
\hline $\mathrm{FEV}, \%($ mean $\pm \mathrm{SD})$ & $92.8 \pm 17.8$ & $94.6 \pm 18.9$ & 0.3 \\
\hline $\mathrm{FVC} \%($ mean $\pm \mathrm{SD})$ & $102.7 \pm 17.8$ & $104.8 \pm 17.4$ & 0.6 \\
\hline $\mathrm{FEV}_{1} / \mathrm{FVC}($ mean $\pm \mathrm{SD})$ & $71.8 \pm 12$ & $72.8 \pm 12.5$ & 0.7 \\
\hline
\end{tabular}

Abbreviations: ILA, interstitial lung disease; $\mathrm{BMI}$, body mass index; $\mathrm{FEV}_{1}$, forced expiratory volume in I second; FVC, forced vital capacity; FEV,/FVC, Tiffenau index. 

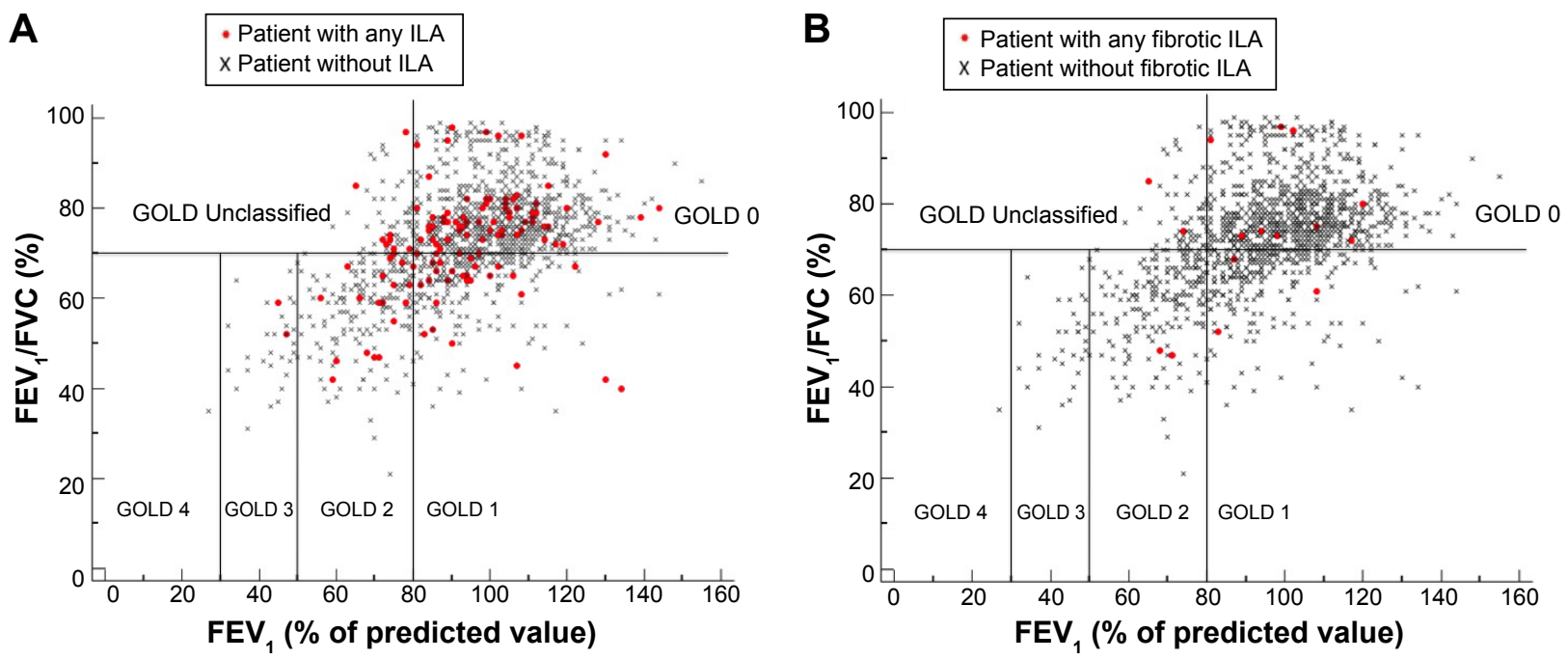

Figure 6 The plots (A and B) show FEV, (percentage of predicted value) plotted against FEV,/FVC (percent of predicted value) for the participants with (red circle) and without any ILA (black cross) and participants with (red circle) and without any fibrotic ILA (black cross), respectively, and classify them according to the GOLD criteria. Abbreviations: FEV $_{1}$, forced expiratory volume in I second; FVC, forced vital capacity; ILA, interstitial lung abnormality; GOLD, Global Initiative for Chronic Obstructive Lung Disease.

participants were nonfibrotic, but $1.8 \%$ participants (12 of 660) met American Thoracic Society and European Respiratory Society criteria for fibrotic ILA. Overall, we reported that $2.8 \%$ of COPD subjects showed fibrotic ILAs but only $0.9 \%$ with definite fibrotic LDCT features. In particular, the definite UIP pattern was not observed in COPD cases, and its prevalence among controls was similar to that reported by prior studies. ${ }^{7,8}$ To our knowledge, this is the first study assessing the prevalence of the probable UIP pattern, which was similar in both cases and controls $(0.9 \%)$. However, in the absence of histologic data, the estimation of the UIP prevalence is not fully reliable. In fact, the LDCT possible UIP pattern may still overlap NSIP and other mixed smokingrelated fibrotic abnormalities in smokers. ${ }^{16,19}$ On the other hand, unilateral reticulation - here scored as equivocal LDCT findings - may still represent unilateral UIP. ${ }^{20}$

Importantly, we showed that male sex and age were the only factors strongly associated with the presence of fibrotic ILA. Such a finding is in keeping with prior studies, notably with the observation of Fell et al $^{21}$ in subjects with UIP. ${ }^{22}$

This is also the first study that assessed the prevalence of the LDCT signs consistent with AEF. The histologic

Table 5 Univariate and multivariate logistic regression models predicting the likelihood of definite ILA

\begin{tabular}{|c|c|c|c|c|c|c|c|c|c|c|}
\hline \multirow[t]{2}{*}{ Variables } & \multicolumn{5}{|c|}{ Univariate } & \multicolumn{5}{|c|}{ Multivariate } \\
\hline & $\beta$ & SE & OR & $95 \% \mathrm{Cl}$ & $P$-value & $\beta$ & SE & OR & $95 \% \mathrm{Cl}$ & $P$-value \\
\hline Age, years & -0.018 & 0.014 & 0.982 & $0.955-1.010$ & 0.208 & & & & & \\
\hline \multicolumn{11}{|l|}{ Sex } \\
\hline Female & - & - & 1 & - & - & & & & & \\
\hline Male & 0.293 & 0.216 & $1.34 \mathrm{I}$ & $0.877-2.049$ & 0.175 & & & & & \\
\hline $\mathrm{FEV}_{1}, \%$ of predicted & -0.003 & 0.005 & 0.997 & $0.987-1.008$ & 0.621 & & & & & \\
\hline $\mathrm{BMI}, \mathrm{kg} / \mathrm{m}^{2}$ & -0.036 & 0.025 & 0.965 & $0.919-1.013$ & 0.148 & & & & & \\
\hline \multicolumn{11}{|l|}{ Smoking status } \\
\hline Former & - & - & I & - & - & - & - & I & - & - \\
\hline Current & 1.456 & 0.301 & 4.289 & $2.380-7.731$ & $<0.001$ & $\begin{array}{l}1.476 \\
(1.400)^{\mathrm{a}}\end{array}$ & $\begin{array}{l}0.302 \\
(0.309)^{\mathrm{a}}\end{array}$ & $\begin{array}{l}4.377 \\
(4.054)^{a}\end{array}$ & $\begin{array}{l}2.422-7.910 \\
(2.214-7.42 \mathrm{I})^{\mathrm{a}}\end{array}$ & $\begin{array}{l}<0.001 \\
(<0.001)^{a}\end{array}$ \\
\hline Pack-years & 0.010 & 0.004 & 1.010 & $1.003-1.018$ & 0.009 & $\begin{array}{l}0.012 \\
(0.014)^{a}\end{array}$ & $\begin{array}{l}0.004 \\
(0.004)^{a}\end{array}$ & $\begin{array}{l}1.012 \\
(1.014)^{\mathrm{a}}\end{array}$ & $\begin{array}{l}1.004-1.020 \\
(1.005-1.022)^{\mathrm{a}}\end{array}$ & $\begin{array}{l}0.004 \\
(0.001)^{a}\end{array}$ \\
\hline \multicolumn{11}{|l|}{ Airflow obstruction } \\
\hline Absent & - & - & I & - & - & & & & & \\
\hline Present & -0.226 & 0.220 & 0.798 & $0.519-1.227$ & 0.303 & & & & & \\
\hline
\end{tabular}

Notes: Hosmer and Lemeshow test shows $\chi^{2}=4.971, P=0.761$ and $\chi^{2}=7.394, P=0.495$ for multivariate and multivariate adjusted models, respectively. ${ }^{a}$ Multivariate adjusted model for presence of airflow obstruction, age, and sex. Statistically significant $P$-values are indicated by bold font.

Abbreviations: ILA, interstitial lung disease; SE, standard error; OR, odds ratio; Cl, confidence interval; FEV , forced expiratory volume in I second; $\mathrm{BMI}$, body mass index. 
Table 6 Univariate and multivariate logistic regression models predicting the likelihood of any fibrotic ILA

\begin{tabular}{|c|c|c|c|c|c|c|c|c|c|c|}
\hline \multirow[t]{2}{*}{ Variables } & \multicolumn{5}{|c|}{ Univariate } & \multicolumn{5}{|c|}{ Multivariate } \\
\hline & $\beta$ & SE & OR & $95 \% \mathrm{Cl}$ & $P$-value & $\beta$ & SE & OR & $95 \% \mathrm{Cl}$ & $P$-value \\
\hline Age, years & 0.160 & 0.028 & I. 174 & $1.111-1.240$ & $<0.001$ & $\begin{array}{l}0.159 \\
(0.165)\end{array}$ & $\begin{array}{l}0.033 \\
(0.03 I)\end{array}$ & $\begin{array}{l}1.172 \\
(1.179)\end{array}$ & $\begin{array}{l}1.098-1.251 \\
(1.109-1.254)\end{array}$ & $\begin{array}{l}<0.001 \\
(<0.001)\end{array}$ \\
\hline \multicolumn{11}{|l|}{ Sex } \\
\hline Female & - & - & 1 & - & - & & & I & & \\
\hline Male & 2.519 & 1.022 & 12.419 & I.675-92.094 & 0.014 & $\begin{array}{l}2.110 \\
(2.150)\end{array}$ & $\begin{array}{l}1.032 \\
(1.032)\end{array}$ & $\begin{array}{l}8.245 \\
(8.582)\end{array}$ & $\begin{array}{l}1.091-62.289 \\
(1.134-64.920)\end{array}$ & $\begin{array}{l}0.041 \\
(0.037)\end{array}$ \\
\hline $\mathrm{FEV}_{1}, \%$ of predicted & -0.008 & 0.010 & 0.992 & $0.972-1.012$ & 0.437 & & & & & \\
\hline BMI, kg/m² & -0.003 & 0.049 & 0.951 & $0.905-1.098$ & 0.951 & & & & & \\
\hline \multicolumn{11}{|l|}{ Smoking status } \\
\hline Former & - & - & 1 & - & - & & & & & \\
\hline Current & -0.452 & 0.407 & 0.636 & $0.287-1.413$ & 0.267 & & & & & \\
\hline Pack-years & 0.013 & 0.008 & 1.013 & $0.998-1.028$ & 0.078 & & & & & \\
\hline \multicolumn{11}{|l|}{ Airflow obstruction } \\
\hline Absent & - & - & I & - & - & - & - & 1 & - & - \\
\hline Present & 0.923 & 0.425 & 2.517 & $1.095-5.787$ & 0.030 & 0.009 & 0.482 & 1.009 & $0.393-2.594$ & 0.985 \\
\hline
\end{tabular}

Notes: Hosmer and Lemeshow test shows $\chi^{2}=7.727, P=0.461$ for multivariate model. Statistically significant $P$-values are indicated by bold font.

Abbreviations: ILA, interstitial lung disease; SE, standard error; OR, odds ratio; Cl, confidence interval; FEV , forced expiratory volume in I second; BMI, body mass index.

features of this fibrotic disorder were initially described in lung specimens obtained from major surgery. ${ }^{23,24}$ Corresponding CT features have been sporadically reported and acknowledged in the latest American Thoracic Society and European Respiratory Society classification of the idiopathic interstitial pneumonias. ${ }^{9,25}$ Watanabe et $\mathrm{al}^{15}$ have recently suggested that AEF may be reliably distinguished from honeycombing. In keeping with their findings, signs consistent with AEF were observed either in association with other ILAs or as the predominant ILA. These abnormalities mostly predominated in the upper lobes and were more frequently observed in subjects with COPD. This relatively higher prevalence might be explained by considering that COPD subjects usually have more severe emphysema, a condition invariably associated with this kind of fibrotic abnormality.

We have also clarified that signs of RB are rarer in smokers with airflow obstruction (4.4\%) as compared to smokers with no airflow obstruction (7.7\%). It is likely that the relatively higher proportion of former smokers among COPD may have accounted to such a difference. In fact, smoking cessation is the most important intervention for the treatment of bronchiolitis as lesions may partially or completely reverse. Smoking cessation is also essential in emphysema to limit extension. ${ }^{26}$

This study has several limitations. Two pairs of observers jointly reviewed two separate groups of CT scans and no interobserver variation could be evaluated. The majority of the study cases had mild-to-moderate airflow obstruction, and data on subjects with severe COPD are scant. No full functional assessment could be performed in most of the study cases, thus limiting the characterization of subjects with ILA. Furthermore, the lack of quantitative data for both pulmonary emphysema and ILA is another important limitation. Such data might clarify how lung fibrosis and emphysema interplay to determine the functional deficit of individual subjects.

\section{Conclusion}

This nested case-control study confirms that there is no association between COPD and definite ILAs. However, fibrotic abnormalities may be appreciated in smokers either with or without airflow obstruction. Future studies might clarify the importance of detecting these ancillary CT findings in COPD.

\section{Acknowledgment}

This work was supported by grants from the Italian Association for Cancer Research (IG research grant 11991) and the Italian Ministry of Health (RF-2010).

\section{Disclosure}

The authors report no conflicts of interest in this work.

\section{References}

1. Celli BR, Decramer M, Wedzicha JA, et al. An Official American Thoracic Society/European Respiratory Society Statement: research questions in chronic obstructive pulmonary disease. Am J Respir Crit Care Med. 2015;191(7):e4-e27.

2. Gershon AS, Mecredy GC, Guan J, Victor JC, Goldstein R, To T. Quantifying comorbidity in individuals with COPD: a population study. Eur Respir J. 2015;45(1):51-59.

3. Smith MC, Wrobel JP. Epidemiology and clinical impact of major comorbidities in patients with COPD. Int J Chron Obstruct Pulmon Dis. 2014;9:871-888. 
4. Turner RD, Gwavava CM, Bianchi SM. Overlooking cardiovascular risk in patients with COPD. Chest. 2011;140(5):1385-1386.

5. Young RP, Hopkins RJ. CT screening in COPD: impact on lung cancer mortality: de Torres JP, Casanova C, Marin JM et al. Exploring the impact of screening with low-dose CT on lung cancer mortality in mild to moderate COPD patients: a pilot study. Respir Med. 2013;107:702-707. Respir Med. 2014;108(5):813-814.

6. Washko GR, Hunninghake GM, Fernandez IE, et al. Lung volumes and emphysema in smokers with interstitial lung abnormalities. NEngl J Med. 2011;364(10):897-906.

7. Jin GY, Lynch D, Chawla A, et al. Interstitial lung abnormalities in a CT lung cancer screening population: prevalence and progression rate. Radiology. 2013;268(2):563-571.

8. Sverzellati N, Guerci L, Randi G, et al. Interstitial lung diseases in a lung cancer screening trial. Eur Respir J. 2011;38(2):392-400.

9. Travis WD, Costabel U, Hansell DM, et al. An official American Thoracic Society/European Respiratory Society statement: update of the international multidisciplinary classification of the idiopathic interstitial pneumonias. Am J Respir Crit Care Med. 2013;188(6):733-748.

10. Jacob J, Hansell DM. HRCT of fibrosing lung disease. Respirology. 2015;20(6):859-872.

11. Silva M, Sverzellati N, Manna C, et al. Long-term surveillance of groundglass nodules: evidence from the MILD trial. J Thorac Oncol. 2012; 7(10):1541-1546.

12. Sverzellati N, Randi G, Spagnolo P, et al. Increased mean lung density: another independent predictor of lung cancer? Eur J Radiol. 2013; 82(8):1325-1331.

13. Rabe KF, Hurd S, Anzueto A, et al. Global strategy for the diagnosis, management, and prevention of chronic obstructive pulmonary disease: GOLD executive summary. Am J Respir Crit Care Med. 2007;176(6): 532-555.

14. Wan ES, Hokanson JE, Murphy JR, et al. Clinical and radiographic predictors of GOLD-unclassified smokers in the COPD Gene study. Am J Respir Crit Care Med. 2011;184(1):57-63.

15. Watanabe Y, Kawabata Y, Kanauchi T, et al. Multiple, thin-walled cysts are one of the HRCT features of airspace enlargement with fibrosis. Eur J Radiol. 2015;84(5):986-992.
16. Raghu G, Collard HR, Egan JJ, et al. An official ATS/ERS/JRS/ALAT statement: idiopathic pulmonary fibrosis: evidence-based guidelines for diagnosis and management. Am J Respir Crit Care Med. 2011;183(6): 788-824.

17. Kondoh Y, Taniguchi H, Ogura T, et al. Disease progression in idiopathic pulmonary fibrosis without pulmonary function impairment Respirology. 2013;18(5):820-826.

18. Alhamad EH, Lynch JP 3rd, Martinez FJ. Pulmonary function tests in interstitial lung disease: what role do they have? Clin Chest Med. 2001; 22(4):715-750, ix.

19. Marten K, Milne D, Antoniou KM, et al. Non-specific interstitial pneumonia in cigarette smokers: a CT study. Eur Radiol. 2009;19(7): 1679-1685.

20. Tcherakian C, Cottin V, Brillet PY, et al. Progression of idiopathic pulmonary fibrosis: lessons from asymmetrical disease. Thorax. 2011; 66(3):226-231.

21. Fell CD, Martinez FJ, Liu LX, et al. Clinical predictors of a diagnosis of idiopathic pulmonary fibrosis. Am J Respir Crit Care Med. 2010;181(8): 832-837.

22. Salisbury ML, Xia M, Zhou Y, et al. Idiopathic pulmonary fibrosis: gender-age-physiology index stage for predicting future lung function decline. Chest. 2016;149(2):491-498.

23. Katzenstein AL, Mukhopadhyay S, Zanardi C, Dexter E. Clinically occult interstitial fibrosis in smokers: classification and significance of a surprisingly common finding in lobectomy specimens. Hum Pathol. 2010;41(3):316-325.

24. Kawabata Y, Hoshi E, Murai K, et al. Smoking-related changes in the background lung of specimens resected for lung cancer: a semiquantitative study with correlation to postoperative course. Histopathology. 2008;53(6):707-714.

25. Caminati A, Cavazza A, Sverzellati N, Harari S. An integrated approach in the diagnosis of smoking-related interstitial lung diseases. Eur Respir Rev. 2012;21(125):207-217.

26. Nakanishi M, Demura Y, Mizuno S, et al. Changes in HRCT findings in patients with respiratory bronchiolitis-associated interstitial lung disease after smoking cessation. Eur Respir J. 2007;29(3):453-461. 


\section{Supplementary materials}

Table SI Individual LDCT features

\begin{tabular}{|c|c|c|c|}
\hline Individual LDCT features & $\begin{array}{l}\text { Subjects with airflow } \\
\text { obstruction ( } n=457 \text { cases) }\end{array}$ & $\begin{array}{l}\text { Subjects without airflow } \\
\text { obstruction ( } n=9 \mid 4 \text { controls) }\end{array}$ & $P$-value \\
\hline Upper lung zone predominance & 29 & 56 & 0.1 \\
\hline Upper middle lung zone predominance & 17 & 41 & 0.07 \\
\hline Lower zone predominance & 13 & 14 & 0.9 \\
\hline Diffuse & 8 & 21 & 0.02 \\
\hline Traction bronchiectasis & 2 & 11 & 0.0001 \\
\hline Honeycombing & - & 2 & $\mathrm{~N} / \mathrm{A}$ \\
\hline Bilateral reticular opacities & 7 & 13 & 0.4 \\
\hline Fluffy centrilobular nodules & 23 & 72 & $<0.001$ \\
\hline Bilateral ground glass opacities & 11 & 4 & 0.02 \\
\hline $\begin{array}{l}\text { Reticular opacities outlining } \\
\text { emphysematous holes }\end{array}$ & 8 & 2 & 0.001 \\
\hline Unilateral reticular opacities & 6 & - & N/A \\
\hline Unilateral ground glass opacities & I & - & $\mathrm{N} / \mathrm{A}$ \\
\hline
\end{tabular}

Abbreviations: ILA, interstitial lung disease; N/A, not applicable; LDCT, low-dose computed tomography.

Table S2 Any ILA or fibrotic ILA distributions across GOLD stages

\begin{tabular}{llllllll}
\hline Presence and type of ILA & \multicolumn{2}{l}{ GOLD stages } & \multicolumn{3}{l}{} & P-value \\
\cline { 2 - 7 } & $\mathbf{0}$ & $\mathbf{I}$ & $\mathbf{2}$ & $\mathbf{3}$ & $\mathbf{4}$ & $\mathbf{U}$ \\
\hline Subjects with no ILA & 787 & 163 & 173 & 58 & 13 & 48 \\
Subjects with any ILA & 75 & 17 & 23 & 6 & 0 & 8 \\
Subjects with no fibrotic ILA & 852 & 177 & 190 & 60 & 13 & 54 & 0.45 \\
Subjects with any fibrotic ILA & 10 & 3 & 6 & 4 & 0 & 2 \\
\hline
\end{tabular}

Abbreviations: ILA, interstitial lung disease; GOLD, Global Initiative for Chronic Obstructive Lung Disease; U, unclassified.

\section{Publish your work in this journal}

The International Journal of COPD is an international, peer-reviewed journal of therapeutics and pharmacology focusing on concise rapid reporting of clinical studies and reviews in COPD. Special focus is given to the pathophysiological processes underlying the disease, intervention programs, patient focused education, and self management protocols.
This journal is indexed on PubMed Central, MedLine and CAS. The manuscript management system is completely online and includes a very quick and fair peer-review system, which is all easy to use. Visit http://www.dovepress.com/testimonials.php to read real quotes from published authors. 